\title{
Paraneoplastic pemphigus and cutaneous squamous cell carcinoma: uncommun 3 cases
}

\begin{abstract}
Paraneoplastic pemphigus is often associated to lymphoproliferative tumors. However, the association of squamous cell carnicoma and pemphigus have been rarely reported in the literature. Here in we report 3 cases of squamous cell carcinoma associated with pemphigus for the rarety of this association.
\end{abstract}

Keywords: pemphigus, squamous cell carcinoma, desmoglein, desmosome
Volume 5 Issue I - 202 I

\author{
Afaf Khouna,' Hazim Aburabie,' Nada Zizi,, \\ Siham. Dikhaye ${ }^{1,2}$ \\ 'Department of Dermatology, Mohammed VI University \\ Hospital of Oujda, Morocco \\ ${ }^{2}$ Department of Epidemiology, Clinical Research and Public \\ Health Laboratory, Morocco
}

Correspondence: Afaf Khouna, Department of Dermatology, Mohammed VI University, Hospital of Oujda, Morocco, Tel+212+664826702,Email afaf.khouna@gmail.com

Received: February 14, 202 I | Published: February 26, 202 I

\section{Introduction}

Paraneoplastic pemphigus (PNP) is an autoimmune eblistering and erosive mucocutaneous syndrome associated with underlying neoplasm. It is primarily associated with lymphoproliferative disorders, and uncommonly with malignancies of epithelial origin. The occurrence of carcinoma is very rare and only 13 cases among 163 PNP have been reported during a period of 13 years. ${ }^{1}$ There are a very few reports of PNP occurring with squamous cell carcinoma. ${ }^{2}$ To our knowledge, one case of pemphigus foliaceus developed after cutaneous squamous cell carcinoma (SCC) metastasized to regional lymphnodes has been reported $^{3}$ and one case of squamous cell carcinoma of the tongue associated with paraneoplastic pemphigus. ${ }^{4}$ Here in, we report 3 cases of squamous cell carcinoma associated with paraneoplastic pemphigus for the rarety of this association.

\section{Cases report}

The first case is a 75 year-old diabetic patient, followed for ischemic heart disease, admitted for cutaneous erosions of the trunk (Figure 1), evolving since 6 months. Anti desmoglein 1 was positive and the biopsy of a blister showed intraepidermalc leavage. The diagnosis of a superficial pemphigus was retained. At the same time, a nodular lesion of the forehead, $1.3 \mathrm{~cm}$ in size (Figure 2), evolving over the past year was noted and the skin biopsy showed a squamous cell carcinoma.

The patient was operated with margins of exeres is at $1 \mathrm{~cm}$ and healthy limits at the histological exam, with normal extension assessment. The patient was treated with prednisolone $1 \mathrm{mg} / \mathrm{kg} / \mathrm{day}$ with a good evolution and progressive degression of corticosteroids, without recurrence of pemphigus or SCC lesions with 2-yearsfollowup.

The second patient was a 45 year-old man, operated for a squamous cell carcinoma of the nose, with healthy tumor margins, 6 months before the installation of deep pemphigus lesions based on clinical examination, histological criteria showing intraepidermal cleavage with a canthosis and immunological criteria showing Anti DSG 1 and Anti DSG 3.

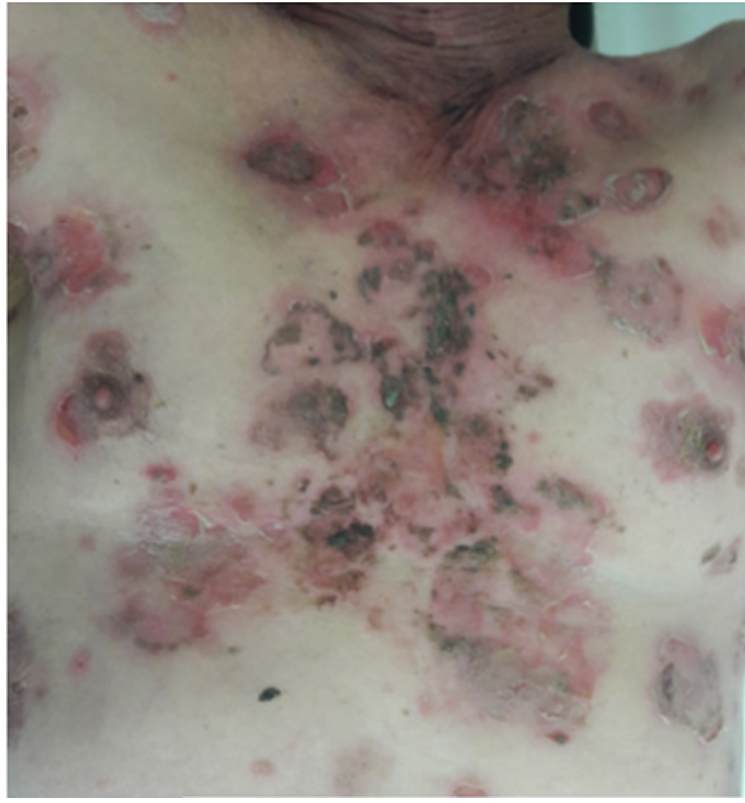

Figure I Cutaneous erosions of the trunk in a patient with paraneoplastic pemphigus and squamous cell carcinoma.

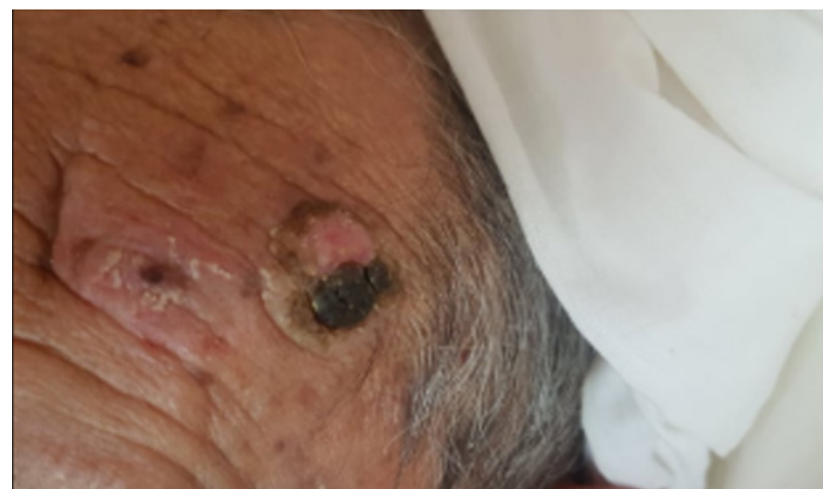

Figure 2 Nodular lesion of the forehead corresponding to a SCC. 
The 3rd patient was 50 year-old, operated for squamous cell carcinoma of the cheek with healthy margins, 18 months before the installation of deep pemphigus lesions confirmed by histological criteria showing intraepidermal cleavage with acanthos is and immunological criteria showing Anti DSG 1 and Anti DSG 3.

Both last 2 patients were treated with prednisolone $1 \mathrm{mg} / \mathrm{kg} /$ day with a good evolution and progressive degression of corticosteroids, without recurrence of pemphigus or SCC lesion with 1 year followup.

\section{Discussion}

Many keratinocyte adhesion molecules are targets of autoantibodies in blistering skin diseases, including the desmogleins in pemphigus foliaceous and vulgaris, and both the plak in molecules and desmogleins in paraneoplastic pemphigus. ${ }^{4}$ It is primarily associated with lympho proliferative disorders, and uncommonly with malignancies of epithelial origin. ${ }^{1}$

The association of pemphigus and carcinomas is very rare. Only few cases of squamous cell carcinoma of the tongue, vagina, hepatocellular carcinoma, esophageal squamous cell carcinoma, lung carcinoma and renal cell carcinoma have been reported in association with PNP. ${ }^{1}$ Cutaneous squamous carcinoma is more rare in association with pemphigus. ${ }^{3}$ A case of bullous pemphigoid in a patient with giant squamous cell carcinoma of the groin has been reported. ${ }^{5}$

Somes studies have shown that the desmosomes are not merelystatic structural entities. They may play an important role in the regulation of cell proliferation, apoptosis and migration. ${ }^{6}$

There are several studies reporting the increased expression of DSG1 and DSG 3 in squamous cell carcinoma of the soft palate, and DSG3 in head and neck squamous cell carcinoma.?

PNP is thought to arise from antibodies directed against tumor antigens that exhibit cross-reactivity against various epidermal proteins.

It has been hypothesized that over expression of DSG3 instead of increasing cell--cell contact strength may be responsible for structural and functional alterations of desmosomes, facilitating cancer cell migration and invasion. ${ }^{6}$

\section{Conclusion}

Despite its rarity, through our cases we would like to shed light on the association of pemphigus with cutaneous squamous cell carcinoma justifying a precise skin examination. For the moment the role of DSG in squamous cell carcinoma is proposed by several authors, requiring large scale studies to establish the causal link.

\section{Conflicts of interest}

There are no conflicts of interest.

\section{Acknowledgments}

None.

\section{Funding}

None.

\section{References}

1. Cho Jin, Kim Nam, Ko Sung, et al. A Case Report of Paraneoplastic Pemphigus Associated with Esophageal Squamous Cell Carcinoma. Cancer research and treatment. 2013;45(1):70-73.

2. Anhalt, Grant J. Paraneoplastic pemphigus. In : Journal of Investigative Dermatology Symposium Proceedings. 2004;9(1):29-33.

3. Inaoki Makoto, Kaji Kenzo, Furuse Shinobu, et al. Pemphigus foliaceus developing after metastasis of cutaneous squamous cell carcinoma to regional lymphnodes. Journal of the American Academy of Dermatology. 2001;45(5);767-770.

4. Wong KC, Ho KK. Pemphigus with pemphigoid-like presentation, associated with squamous cell carcinoma of the tongue. Australasian journal of dermatology. 2000;41(3):178-180.

5. Reich Adam, Szepietowski JC, Bialynicki-Birula R, et al. Bullous pemphigoid in a patient with giant squamous cell carcinoma of the groin. Acta Dermatovenerologica Alpina, Pannonica et Adriatica. 2004;13:5862.

6. Alaibac Mauro. Targeting DSG3: From pemphigus to squamous cell carcinoma. Expert opinion on therapeutic targets. 2013;17.

7. Maumi Yoshifumi, Suzaki Reiko, Ito Naoko, et al. Squamous cell carcinoma of the soft palate associated with autoantibodies to desmoglein 1 and 3. Dermatology practical \& conceptual. 2013;3(4):555-557. 